\title{
Potencial Hídrico de las Microcuencas del Río Viejo
}

\author{
Yelba Flores Meza1, Jorge Guatemala Herrera 2
}

Centro para la Investigación en Recursos Acuáticos de Nicaragua, CIRA/UNAN-Managua. 1 yelba.flores@ cira-unan.edu.ni, 2 jorge.guatemala@ cira-unan.edu.ni

Recibido: 20 de octubre 2012 / Aceptado: 3 de diciembre 2012.

\section{RESUMEN}

Se ha calculado el potencial hídrico a través de la evaluación de las condiciones físico-naturales, que definen la ocurrencia y el movimiento del agua superficial y subterránea. Debido a las particularidades de cada zona, se ha dividido la microcuenca del Río Viejo en parte alta, media y baja. Para la parte alta es determinante para la producción hídrica, el relieve abrupto, con pendientes de hasta $35^{\circ}$, el terreno intensamente deformado y el uso de suelo, con áreas en recuperación. El potencial total de producción hídrica es de 593MMC de escorrentía superficial y 174.51MMC de recarga anual. La parte media se presenta menos deformada, con pendientes que sobrepasan $\operatorname{los} 30^{\circ}$ y en general con uso de suelo para ganadería. La escorrentía superficial se ha calculado en 556MMC anuales y la recarga en 125.9MMC anuales.

Para la parte baja es notoria la influencia del Lago de Apanás. El escurrimiento superficial para la parte baja es de 108.6MMC anuales, debido a la poca extensión de sus microcuencas. La recarga es mayor con un volumen de 266.9MMC, dada la alta deformación de las rocas. La zonificación de potencial hídrica, referida a la producción por $\mathrm{Km}_{2}$ de microcuenca, se basó en la metodología de Matus Silva, OD 2007, CATIE., para la recarga y adaptada para el potencial. La parte alta de Río Viejo, refleja las mejores condiciones para la recarga. La parte media tiene zonas de producción hídrica moderada y baja y la parte baja, presenta el rango de moderada a baja.

Palabras Claves: Geología, Suelo, Potencial Hídrico, Zonificación.

\section{INTRODUCCIÓN}

El Proyecto Integral de Manejo de Cuencas Hidrográficas, Agua y Saneamiento (PIMCHAS) tiene como propósito desarrollar capacidades, herramientas y condiciones locales para una gestión integrada y el desarrollo económico de la población que vive en las subcuencas de intervención. Una de estas subcuencas es la del Río Viejo. En este contexto y para lograr los alcances del Proyecto, es necesario contar con la información técnico-científica necesaria que apoye la toma de decisiones. La producción hídrica es uno de los beneficios principales que proveen las cuencas hidrográficas, por lo que el conocimiento del potencial, se considera primordial en la GICH. Así, se estableció el convenio entre el Centro para la Investigación en los Recursos Acuáticos de Nicaragua (CIRA/UNANManagua) y el Proyecto PIMCHAS, liderado por MARENA, para ejecutar el diagnóstico del estado de los recursos hídricos en el Río Viejo.

El enfoque de trabajo, es la determinación de cada uno de los parámetros principales del balance hídrico superficial y subterráneo, para conocer la producción hídrica. Se utilizaron diferentes metodologías, escogidas de forma tal, que reflejen, lo más claramente posible, la interrelación entre el medio físico-natural y la producción hídrica. Así, se obtuvieron los volúmenes de producción referidos al tipo y uso de suelo, condiciones geológicas y condiciones meteorológicas.

El resultado es la producción hídrica por área y microcuenca. La localización espacial de las áreas de mayor producción hídrica, permitirá al Proyecto PIMCHAS, enfocar los esfuerzos en mantener estas áreas y recuperar las zonas que han disminuido su producción por efectos de uso de suelo.

\section{MATERIALES Y MÉTODOS}

Para cumplir con los objetivos planteados se dividió el trabajo en diferentes etapas:

Recopilación de información secundaria, principalmente datos obtenidos por digitalización de mapas topográficos, geológicos, imágenes de satélites, registros meteorológicos. Algunos informes antecedentes del funcionamiento de las presas de Apanás-Asturias y La Virgen, acuífero Valle de Sébaco y San Francisco Libre.

Una vez analizada la información existente, se verificaron los datos de campo a través de reconocimiento geológico e hidrogeológico, lo que sirvió para seleccionar los sitios de monitoreo de ríos, pozos y manantiales. En esta etapa se realizó la verificación general de tipo y uso de suelo, con la finalidad de actualizar la información existente.

Se midió el caudal del río en los tributarios principales y cauce principal durante el período Nov 2010- Dic 2011, abarcando un año hidrológico. El monitoreo incluyó la medición de niveles estáticos de pozos comunitarios y caudal de manantiales de abastecimiento humano.

Se complementó la investigación de la ocurrencia del recurso hídrico con la realización de 22 pruebas de 
infiltración de suelos para la determinación de la recarga hacia los acuíferos.

Los datos se incorporaron a las ecuaciones de balance hídrico superficial y subterráneo, para obtener el potencial hídrico de la microcuenca. De acuerdo a la producción hídrica, se ha realizado la zonificación de las microcuencas del Río Viejo. La escala es de 1-4, representando el 4 una Producción Hídrica Alta. Se considera la recarga como el componente más vulnerable del balance hídrico. Este parámetro es el que mantiene los caudales bases de los ríos y los niveles de los pozos, por lo tanto, reviste una alta importancia en la disponibilidad de Agua. Se valoran los volúmenes de Recarga y Caudal producido de 1 a 4 . A mayor recarga el valor aumenta, a mayor caudal el valor disminuye, por considerarse, que los caudales medidos son instantáneos y no reflejan el aporte subterráneo, como un indicador de infiltración.

Debido a la heterogeneidad de las microcuencas, en forma, tamaño, uso de suelo, tipo de suelo, tipo de roca y fracturamiento, se toma la producción superficial y subterránea por $\mathrm{Km}_{2}$ de Microcuenca. Se ha tomado directamente la producción, puesto que en los cálculos, ya ha sido considerado las características físicas, que determinan el volumen de recarga y escorrentía superficial. Se ponderan los valores con un coeficiente de 0.8 para la recarga y 0.2 para la escorrentía. Se suman los valores y se tiene una escala de Producción Hídrica, relacionada a la infiltración del terreno. Los rangos se generan a partir de los máximos y mínimos obtenidos para toda la subcuenca. Tabla 1.

Tabla 1 Valoración por Producción Hídrica. Subcuenca Río Viejo. Nov. 2009 - Dic. 2010 (m³/s).

\begin{tabular}{|l|r|l|r|}
\hline $\begin{array}{c}\text { Recarga } \mathrm{MMC} \\
\text { anuales } / \mathrm{Km}^{2}\end{array}$ & Valor & $\begin{array}{c}\text { Caudal MMC } \\
\text { anuales/Km }\end{array}$ & Valor \\
\hline Después de 1000 & 4 & Menos de 1MMC & 4 \\
\hline Hasta 500 & 3 & Hasta 10 & 3 \\
\hline $500-100$ & 1 & Hasta 15 & 2 \\
\hline Menos de 100 & 1 & Después de 15 & 1 \\
\hline
\end{tabular}

\section{RESULTADOS}

Se ha dividido la subcuenca del Río Viejo en tres partes principales, que reúnen características similares: Parte alta, Media y Baja.

La Parte alta, con aproximadamente $350 \mathrm{Km}_{2}$, de área, se presenta montañosa. Las alturas sobrepasan los 1700msnm. El terreno es accidentado, con relieve inclinado a moderadamente escarpado y pendientes de hasta $35^{\circ}$. Los valles importantes son San Rafael, La Concordia, Valle de Valerio, Llanos de Colón, Isiquí-Los Encuentros y Namají. Predominan las rocas basálticas y dacíticas. Las estructuras se presentan entrecruzadas en una rejilla con dirección predominante este-oeste y lineamientos noreste-suroeste. Las rocas han formado suelos Molisoles, lo que ha dado lugar a una intensa actividad agropecuaria, actualmente en abandono. Algunos terrenos están en recuperación y solo un pequeño porcentaje (9\%), representa el bosque primario. El total de recarga para la Parte alta es de 174.51MMC anuales. La escorrentía superficial se ha calculado en 593MMC. Se distinguen zonas potenciales alta y moderada. El potencial hídrico es mayor en las Microcuencas Viejo Colon Arriba y las Localizadas entre el San Marcos y Santa Bárbara. (ver figura 1).

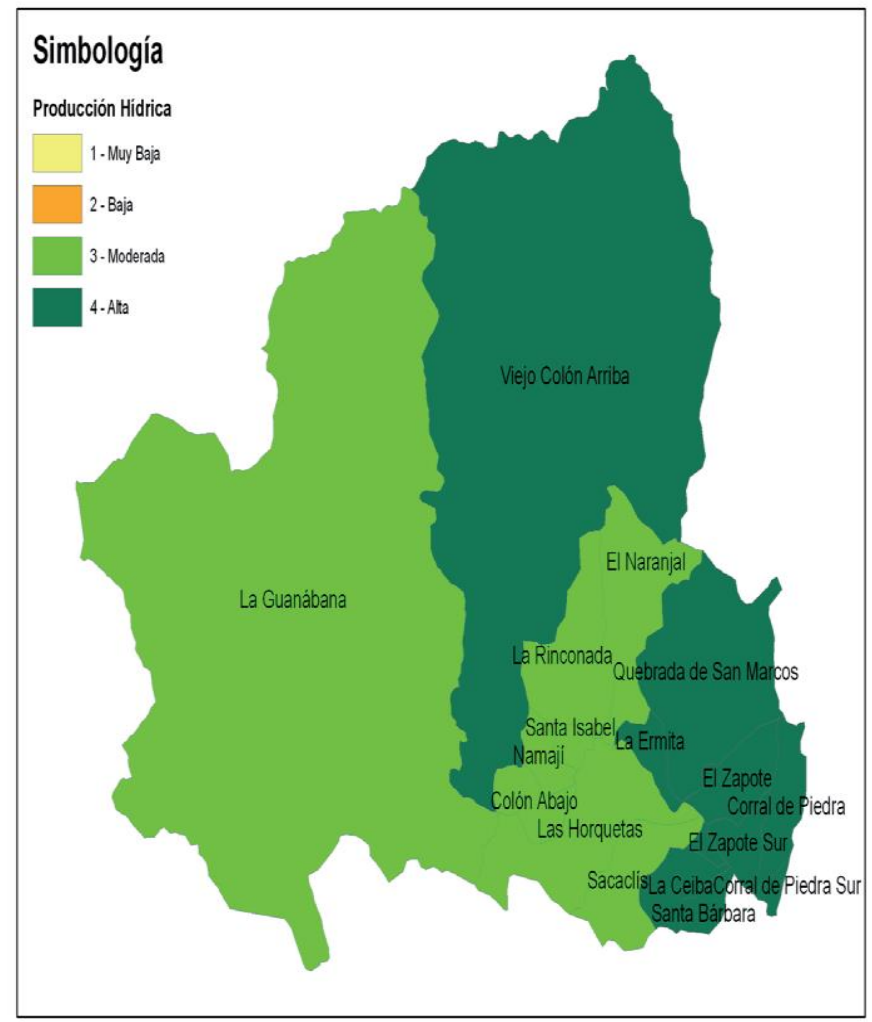

Figura 1. Rango de Producción Hídrica. Parte Alta Río Viejo

La Parte media, con un área aproximada de $315 \mathrm{Km}_{2}$, es menos accidentada y de composición homogénea, principalmente basaltos, las pendientes sobrepasan los $30^{\circ}$. El terreno es moderadamente escarpado a escarpado. La parte media está dominada por rocas compactas y uso de suelo agrícola. . En la parte media la zona de ganadería supera el $65 \%$, aumentando sin embargo, el área boscosa con poco más de $15 \%$. No se distinguen acuíferos productivos. El total de recarga para la Parte 
media es de 125.90MMC anuales. La escorrentía superficial se ha calculado en 556MMC anuales. De acuerdo a la Zonificación se distinguen zonas de producción hídrica baja y moderada. Siendo las cuencas extremas al norte y sur las más productivas. Figura 2.

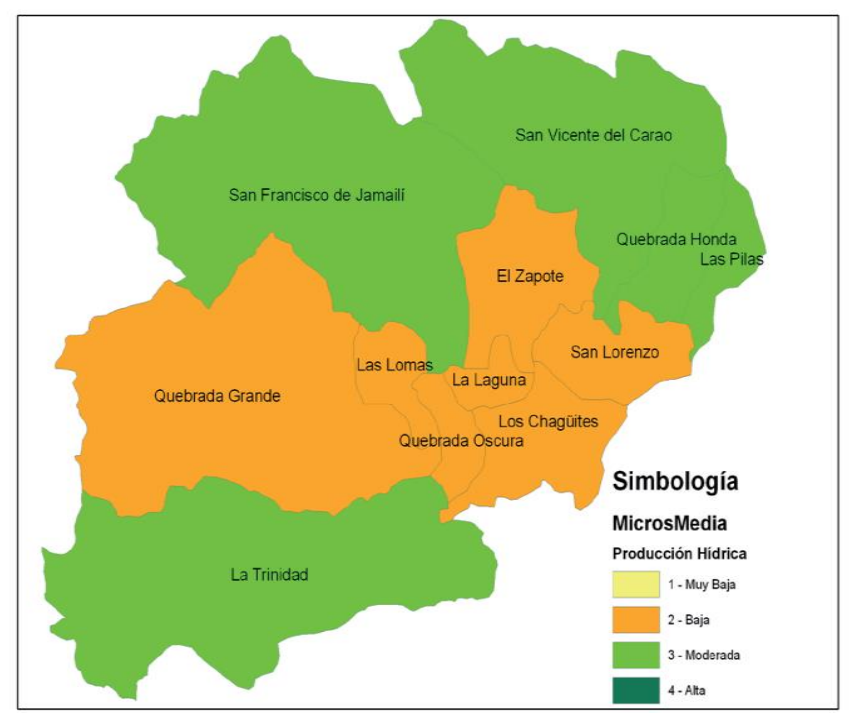

Figura 2. Rango de Producción Hídrica. Parte Media Río Viejo.

La parte baja de la Microcuenca cubre un área aproximada de $890 \mathrm{Km}_{2}$, es una zona bien accidentada. Las pendientes, aunque localmente, alcanzan inclinaciones de hasta $90^{\circ}$.

Se destacan el Valle de Sébaco al centro y el Valle de San Francisco Libre al sur. El cerro La Cruz es el sitio más elevado con $1351 \mathrm{msnm}$. En la parte baja, dominan los cultivos con $17 \%$ del área total. Se observan algunos esfuerzos de reforestación con pinares. El escurrimiento superficial para la parte baja es de 108.6MMC anuales y el total de recarga de 266.09MMC anuales. Se distinguen zonas de producción de muy baja a moderada, dominando el rango Bajo, esto debido al uso de suelo. Figura 3.

\section{DISCUSIÓN}

La evaluación de las condiciones naturales, geología y uso de suelo, ha posibilitado la identificación de las microcuencas más productivas. Se realizó la zonifican hídrica, tomando en cuenta la producción por $\mathrm{Km}_{2}$ de microcuenca, enfatizando en la recarga. Este parámetro se considera el más importante, ya que determina el agua hacia el acuífero y mantiene el caudal base de los ríos. La parte alta de Río Viejo, refleja las mejores condiciones para la recarga. Aquí solo se obtuvo, casi en el mismo porcentaje zonas alta y moderada de recarga. La parte media, muestra condiciones de producción hídrica moderada y baja, debido a las condiciones de terreno y uso de suelo. La parte baja, presenta el mosaico casi completo de zonificación, a excepción de la zona de producción alta, dominando principalmente la clasificación baja. Se presentan para las tres partes de la subdivisión de la subcuenca del Río Viejo,

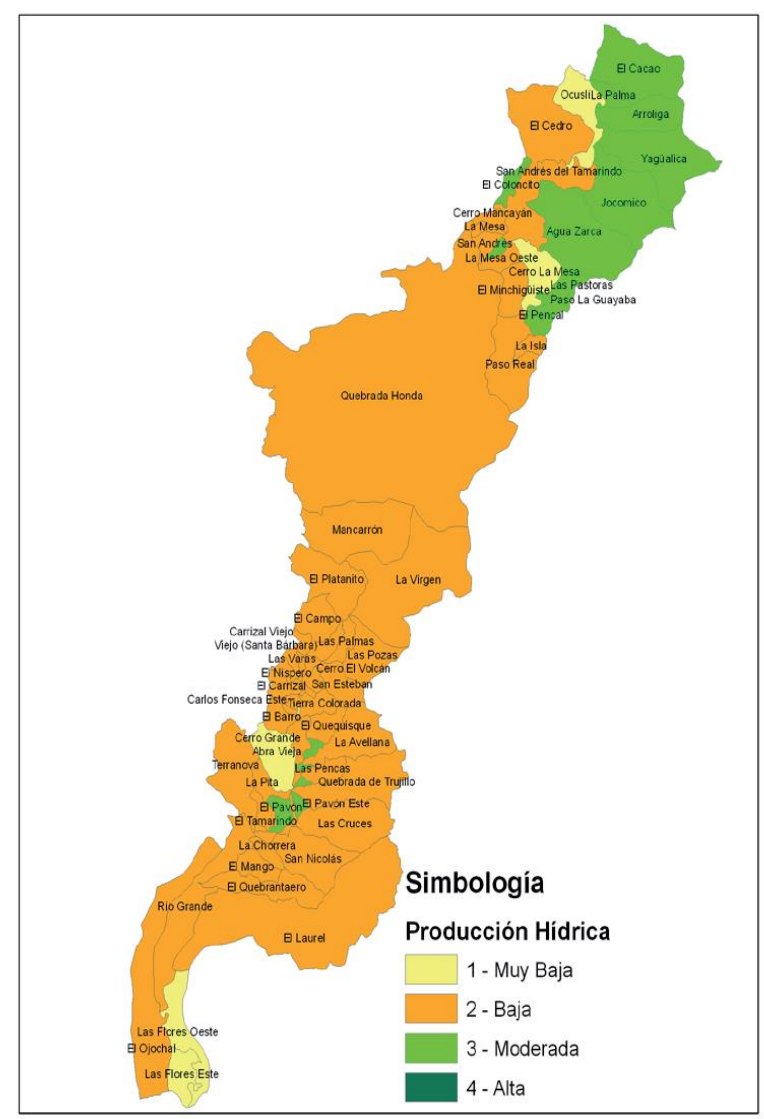

Figura 3. Rango de Producción Hídrica. Parte Baja Río Viejo.

\section{CONCLUSIONES}

Tanto las características físico-naturales como las actividades de uso de suelo, influyen en la producción hídrica de la subcuenca del Río Viejo.

En total el escurrimiento para todo el Río Viejo, se calcula en 1258.11MMC anuales. La recarga total es de aproximadamente 566.52MMC anuales, volumen que alimenta a los acuíferos, muy por debajo de la Escorrentía. Las acciones deben encaminarse a aumentar este volumen, tanto de reforestación como de manejo de suelos.

La parte alta de Río Viejo, refleja las mejores condiciones para la recarga, con potencial alto y moderado. En la parte media, se obtienen zonas de producción hídrica moderada y baja. La parte baja, presenta zonas de producción de muy baja a moderada, dominando el rango Bajo.

\section{RECOMENDACIONES}


Es necesario impulsar trabajos meteorológicos, geológicos, hidrogeológicos e hidrológicos a detalle.

Promover la implementación de pequeñas presas para aprovechar la escorrentía.

Implementar planes de manejo de suelos para su recuperación.

\section{BIBLIOGRAFÍA}

Custodio E. Llamas M. 1976. Hidrología Subterránea.

Ediciones Omega S.A., Barcelona. Primera

Edición.

Tomo I y II INETER, 1985.Base Topográfica 1:50000

Kuang, 1971. Mapas Geológicos. 1:50000
MAGFOR, 2005. Mapas de Tipo y Uso de Suelo. 1:50000

Matus, Silva. OD, 2007. Elaboración participativa de una metodología para la identificación de zonas potenciales de recarga hídrica en subcuencas hidrográficas, aplicada a la subcuenca del río Jucuapa, Matagalpa Nicaragua.

Schosinsky G. \& Losilla M. 2000. Revista Geológica de América Central. No. 23. Universidad de Costa Rica. Diciembre 2000. Ed. Universidad de Costa Rica.

TERRENA. Proyecto TERRENA. Caracterizaciones municipales. Publicaciones en http://www.terrena.org 